Lidija Barjaktarovic ${ }^{1}$, Katarina Djulic ${ }^{2}$, Renata Pindzo ${ }^{3}$, Ana Vjetrov ${ }^{4}$

1, 2, 4 Faculty of Economics, Finance and Administration, FEFA

${ }^{3}$ Ministry of Trade, Tourism and Telecommunication

\title{
Analysis of the Capital Budgeting Practices: Serbian Case
}

UDC: 657.31

005.22:334.7(497.11)"2015"

DOI: 10.7595/management.fon.2016.0009

\begin{abstract}
This paper addresses two major research questions: which techniques firms in Serbia use for project evaluation, and how the Serbian companies calculate their cost of capital. The authors have created the questionnaire and the sample consisting of 65 companies that responded to the enquiry (out of 392) during the year 2015. The results showed that payback criterion is the most dominant capital budgeting technique used by firms in Serbia. Further, the results revealed that large firms as well as multinational firms are more inclined to use discounted cash flow capital budgeting techniques and other sophisticated techniques. Finally, the authors have concluded that the CAPM is not the dominant method for calculating cost of capital by the companies from the sample analyzing the overall sample. Consequently, skilled human capital, the adequate knowledge and developed procedures may contribute to accepting capital budgeting techniques such as discounted cash flow analysis and other sophisticated techniques by larger portion of the companies in Serbia. Finally, existence of perfect financial market is a necessary precondition for implementing all these contemporary financial concepts and its development has to be posed as one of the priorities in the years to come.
\end{abstract}

Keywords: capital budgeting, capital budgeting techniques, CAPM, ownership, size of firms.

\section{Introduction}

Development of the enterprises depends on their investment policies and their actual implementation. Apart from the necessary financial means, it is advisable that the company uses certain capital budgeting techniques that will reduce the possibility for accepting unprofitable projects, especially within general trend of illiquidity of the Serbian economy. Thus, the focus of this paper will be on the investments on firms' level and on capital budgeting techniques that companies and their CFOs (Chief Executive Officers) apply when evaluating new projects.

Specifically, the aim of this paper is to determine which capital budgeting techniques are most frequently used by the firms in Serbia when evaluating investment projects including various business risks (sample of 65 companies, leaders in their industries) in 2015. To gauge the investment evaluation process in Serbia and assess its adequacy (in terms of companies' characteristics), we will compare our results with the results obtained from similar surveys conducted in the United States of America (USA), Canada, Western Europe and Central and Eastern Europe (CEE).

The following hypotheses will be tested:

H1: Payback criterion is the dominant investment evaluation technique in Serbia.

H2: Factors such as size and ownership may influence the choice of capital budgeting technique.

H3: The CAPM model is not the dominant model for estimating the cost of capital in Serbia.

This paper will be structured as follows: within the first section we present literature review along with relevant 
findings of similar surveys in different countries and regions. In section two, the methodology is presented, including a detailed description of our questionnaire. Within the third section, the results of our survey are presented and simultaneously compared to prior research in the USA, Canada, Western Europe and Central and Eastern Europe. In the end, we present the conclusions.

\section{Literature Review}

This paper addresses two major research questions: which techniques firms in Serbia use for project evaluation, and how the Serbian companies calculate their cost of capital.

There was a number of surveys that examined these questions. For instance, Graham et al. (2001) have found out (in the sample of 4,440 companies and 392 CFOs in the USA and Canada) as follows: (a) most firms within the sample use the present value techniques for evaluating new investments; (b) firms frequently use company-wide discount rates in comparison to a project-specific discount rate; (c) large firms are more inclined to use both net present value as the main capital budgeting technique and the Capital Asset Pricing Model (CAPM) for cost of capital in comparison to small companies. However, ignoring the company size, one general rule apply for all and that is the fact that managers should invest in every project they know to have a positive Net Present Value /NPV/ (Myers et al., 1984).

Furthermore, Danielson et al. (2006) have found out (the survey included 792 small-sized companies in USA) than many small firms evaluate new investments using the payback criterion or even the owner's gut feel. The reason is limited education background of some owners and small staff sizes. Liquidity concerns and cash flow estimation challenges are the key reasons why small companies avoid using discounted cash flow techniques to evaluate projects. Once again, the results confirm that the size of the firm may influence the choice of project evaluation procedures. Further, it is important to bear in mind that the capital budgeting decision process remains one of the main decision areas confronting the contemporary financial manager, since its results help influence the firm's future opportunities (Gitman et al., 1977). Consequently, it stresses the importance of the usage of capital budgeting techniques in everyday activities.

Vijay et al. (1995) connected research results (133 large Canadian companies) indicate that: (a) Canadian firms most frequently used DCF methods as well. (b) Sensitivity analysis represents a frequently used technique for cash flow estimation along with management subjective estimates. (c) The standard models used for calculating the cost of capital are the CAPM and the dividend growth model. However, the results also show that the companies are prone to rely on non-standard methods for calculating the cost of capital.

Brounen et al. (2004) did the same survey as Graham et al., this time in Europe (on a sample of 313 European CFOs). The results obtained in the survey imply that that European firms are keener on using the payback criterion, in comparison to DCF (discounted cash flow) techniques such as NPV or internal rate of return (IRR). These results crucially differ from the results acquired by Graham and Harvey in the USA: a) In determining the cost of capital there are certain similarities between European firms and US companies (CAPM appears to be the most frequently used model for estimating the cost of capital in comparison to historical average of returns or the dividend discount model). b) Furthermore, the results confirm that the firm size positively correlates with the implementation of DCF methods and the CAPM, i.e. larger firms are more inclined to use these techniques.

Moreover, Andor et al. (2011) did some research for the CEE (a sample of 10 countries: Bulgaria, Croatia, the Czech Republic, Hungary, Latvia, Lithuania, Poland, Romania, the Slovak Republic, and Slovenia). The results unanimously show that within the CEE region: (a) the firms' most important goals are liquidity and stability of cash flows; (b) Approximately $17 \%$ of the companies within the sample do not apply formal written capital budgeting procedures, while $61 \%$ of the respondents that implement the latter use DCF techniques (NPV and IRR); (c) There is a preference for the payback criterion, as in Western Europe; (d) The corporate finance practice is influenced by the firm size and its ownership. Consequently, large firms and multinational companies are more inclined to use a DCF analysis and more sophisticated techniques in comparison to smaller companies; (e) Larger companies are more frequently using the CAPM.

Finally, Dedi et al. (2007) did a similar survey in Croatia (a sample of 234 selected legal entities), which is 
the most similar to Serbia (historically, culturally and geographically connected). The results reveal that: (a) $22 \%$ of the firms from the examined sample most frequently use NPV and IRR while $24 \%$ of the companies often use IRR and the payback period (similar to the results obtained in the CEE region); (b) $76 \%$ of the respondents have stated that they estimate the cost of capital using some formal technique, $40 \%$ of the respondents calculate the cost of capital according to the investors' required return, $9 \%$ use the CAPM, and $40 \%$ determine the cost of capital using the WACC; (c) The usage of the CAPM is very low (coincides with the results obtained in the CEE region); (d) $81 \%$ of the companies regularly did project cash flows' estimations, and $73 \%$ of the companies assessed the project risk; (e) $42 \%$ of the companies used a riskadjusted discount rate.

In the section Results we will use the presented findings of our survey and comparethem to the presented results in different countries and regions.

\section{Methodology}

The authors have created a questionnaire (based on Graham and Harvey survey in 2001) comprised of four sections (45 questions): capital budgeting techniques and cost of capital, capital structure and pecking order theory, dividend policy and enterprise risk management concept (ERM concept). This paper focuses on two areas and hence the first section of the questionnaire (15 questions): capital budgeting techniques and the cost of capital.

Our sample consists of 65 companies that replied to our enquiry (out of 392) during 2015. The aim was to cover most of the industries within the country and to include as many companies as possible varying in their size and ownership. Within the sample, the companies range from micro to large companies (34\% micro, $20 \%$ small, $20 \%$ medium, and $26 \%$ large). ${ }^{1}$

Furthermore, the analysis of the ownership shows that $40 \%$ of the companies within the sample are foreignowned firms and $60 \%$ are domestic ones. In the end, $25 \%$ of the firms in our sample are manufacturers. The non-manufacturing firms are equally distributed across other industries: financial (20\%), retail and wholesale $(20 \%)$, tourism and hotels (15\%), telecommunication (5\%), IT sector $(5 \%)$ and consulting companies (10\%). We have analyzed responses according to the companies' characteristics (size, ownership, industry). The period of analysis is 2015 .

The respondents were asked: (a) to score how often they use various capital budgeting techniques when evaluating whether they should accept or reject a project. They had to rate the frequency by using a scale of 1 to 5 ( 1 meaning "never", 5 meaning "always"); (b) whether they have an investment and development policy; (c) to answer if they make business plans and if they do projections of cash flows before making an investment decision; (d) the ways of calculating the project cost of capital; (e) to rate the frequency of implementing each method (CAPM, discounted dividend model etc.) using the described scale of 1 to 5; (f) about measures the frequency of risk adjustments of the discount rate and cash flows. The same method is used, i.e., the CFOs had to describe the frequency of taking each risk factor into consideration for cash flow and discount rate adjustments. The revew of the draft of the questionnaire was done by financial experts. The questionnaires were then sent to CFOs by mail.

Finally the answers were processed in the SPSS statistical program. The results are presented in the following section.

${ }^{1}$ According to the Law on Accounting and auditing, the enterprises are classified into the following categories:

Micro: (annual average number of employees /AANE/ 1 10; annual sales /AS/ $\leq$ RSD 84,671,000 and annual average asset value/AAAV/ $\leq$ RSD 42,335,000); Small: (10 $\leq$ AANE $\leq$ RSD 50;84,671,000 $\leq$ AS $\leq$ RSD 1,064,433,000; RSD 42,335,000 $\leq$ AAAV $\leq$ RSD 532,217,000); Medium: (50 $\leq$ AANE $\leq$ 250; RSD 1,064,433,000 $\leq$ AS $\leq$ RSD 4,233,541,000; RSD 532,217,000 $\leq$ AAAV $\leq 2,116,770,000$ ); Large: (AANE $\geq 250 ;$ AS $\geq R S D$ $4,233,541,000$ and $A A A V \geq 2,116,770,000)$; 


\section{Results}

The results referring to the choice of capital budgeting techniques $(\mathrm{H} 1)$ are summarized in Figure 1.

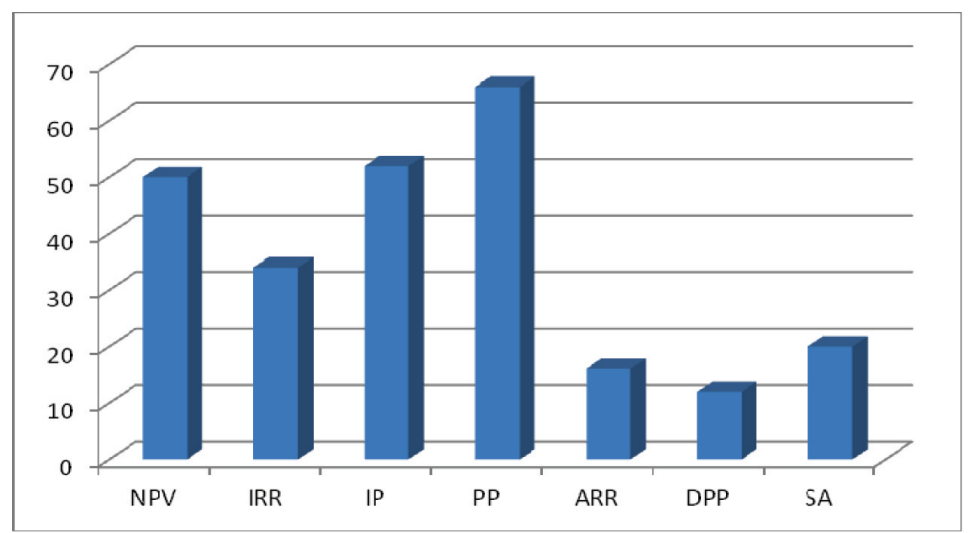

Figure 1: Percentage of respondents (CFOs) who always or often use given capital budgeting techniques (Results from the survey conveyed by the authors)

As presented, most respondents, in evaluating their investment projects, use the Payback Period (PP) - 66\% of them, the Profitability Index (PI) is used by $52 \%$ and NPV is used by $50 \%$ of the surveyed. Furthermore, $34 \%$ of Serbian CFOs always or often use techniques such as IRR. Finally, the least used techniques by the respondents are the Sensitivity analysis (SA), the Discounted Payback Period (DPP) and the Accounting Rate of Return (ARR). The rare usage of more advanced methods such as sensitivity analysis may be expected in the companies in Serbia.

Our results are most similar to the results of Andor, Mohanty and Toth (2011) in the CEE. The results indicate that the mostly used capital budgeting technique in the CEE is the PP $(66 \%)$, an accounting based method such as the ARR (60\%) and finally, discounted cash flow techniques such are the NPV and the IRR $(52 \%$ and $50 \%$, respectively). The reason for frequent usage of the PP criterion both in Serbia and in the CEE regions is its close relation to liquidity. In Serbia, inefficient and poorly developed financial markets have led to less frequent usage of discounted cash flow techniques. Consequently, our $\mathrm{H} 1$ is confirmed, regarding the PP as the most dominant capital budgeting technique used by firms in Serbia.

The results of testing $\mathrm{H} 2$ are presented in Figure 2.

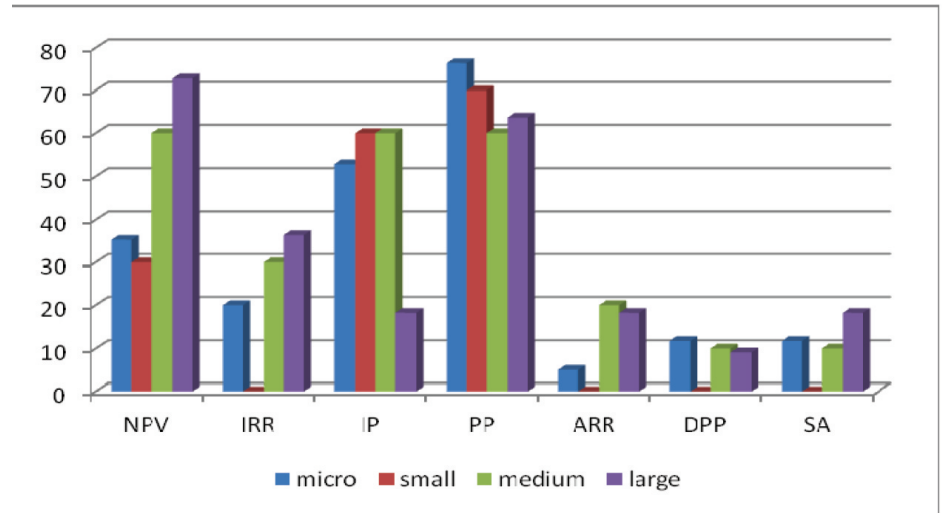

Figure 2: Percentage of respondents (CFOs) who always or often use given capital budgeting techniques according to firm size (Results from the survey conveyed by the authors)

The results clearly indicate that larger firms are more inclined to use discounted cash flow techniques (DCF) such as NPV and IRR in comparison with smaller firms. Furthermore, larger firms are more frequently using advanced techniques such as the SA. However, the implementation of the SA technique while evaluating a 
project is still on a poor level in comparison with the companies in the USA and Canada. The PP criterion and $\mathrm{PI}$ are more used in smaller companies in comparison with larger ones. The results completely coincide with the survey conducted by Harvey and Graham in 2001 and Andor et al. (2011). Furthermore, the following figure shows the influence of foreign ownership on capital budgeting technique implementation.

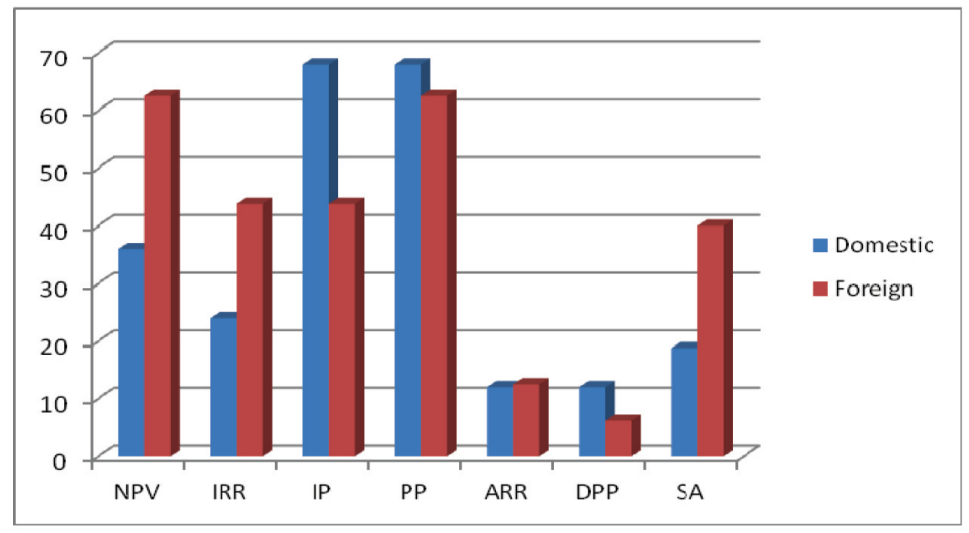

Figure 3: Percentage of respondents (CFOs) who always or often use given capital budgeting techniques according to the ownership (Results from the survey conveyed by the authors)

The results in Figure 3 confirm the findings related to the prior research, which state that large firms as well as multinational firms are more inclined to use DCF capital budgeting techniques and other sophisticated techniques. Furthermore, $40 \%$ of the respondents working in foreign-owned companies frequently use the sensitivity analysis when evaluating project. The latter is higher in comparison to the average usage of the SA $(20 \%)$ in our sample consisting of 65 companies.

If we compare the results from our survey with the surveys conducted in both the USA and the CEE region, we can see that there is a similarity between the findings. Finally, our $\mathrm{H} 2$ has been confirmed regarding the importance of factors such as size and ownership for the choice of the capital budgeting technique. The results of testing $\mathrm{H} 3$ are presented in Figure 4.

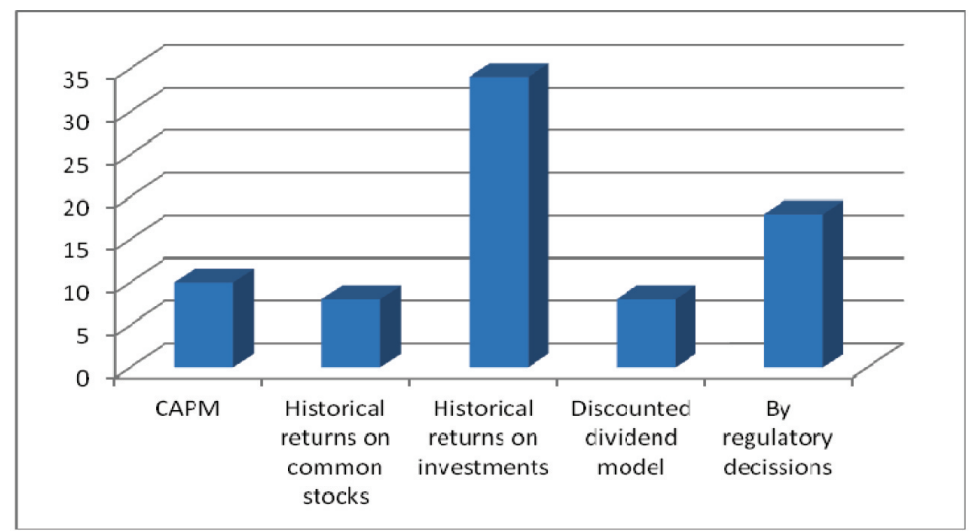

Figure 4: Percentage of CFOs who always or often use a given method (Results from the survey conducted by the authors)

The next question which will be analyzed is how firms calculate the cost of capital. The results clearly show (Figure 4) that the most common model used for determining the cost of capital is historical returns on prior investments (34\% of the sample). The frequent usage of this technique in comparison to the others is not surprising because it is easily understood by all. However, $48 \%$ percent of the respondents stated that upon determining the discount rate for each investment, they made a difference between the risk at the company level and the risk for that particular investment. Furthermore, the respondents stated that they most frequently used the cost of capital as determined by a regulatory decision (18\%) and the CAPM (10\%). However, the 
frequency of the usage of any given technique is below $50 \%$, implying the necessity of increasing the general knowledge regarding the cost of capital, its calculation, importance etc. Moreover, it is crucial to emphasize that a larger percentage of the firms within the sample are private firms and their beta could only be calculated through analyzing comparable publicly traded companies, which in Serbia presents a great challenge. The capital market in Serbia is not efficient and liquid in comparison with capital markets in the USA and Europe, which is the key obstacle in implementing the CAPM in the Serbian companies.

Our survey in Serbia has similar results as: 1) Dedi et.al in 2007 (sample of 45 firms in Croatia). They found out that that $76 \%$ of the companies estimated their cost of capital, $40 \%$ used a cost determined by investors' expected returns, $9 \%$ used the CAPM, and $40 \%$ determined the cost of capital using the WACC. Further, all the companies within the sample do not use only one model for the calculation of cost of capital. Additionally, the survey revealed that $81 \%$ of the companies estimate project cash flows before deciding upon rejecting or accepting the investment. In Serbia, $88 \%$ of the respondents stated that they did projection of cash flows regarding particular investment, which is a necessary precondition for further deciding upon the feasibility of the investment project. 2) Andor et al. in 2007 in the CEE, revealed the fact that most of the companies did not actually calculate the cost of capital. Instead, they were inclined to use a general discount rate. The survey revealed that $80 \%$ of the companies were using general discount rate, while small percentage of the companies used the CAPM (9\%). Finally, the results from our survey indicate that large and medium firms and foreign firms are more inclined to use the CAPM $(17 \%, 15 \%$ and $14 \%)$ in comparison with small and micro and domestic ones (6\%, 5\% and $7 \%)$. Furthermore, the results show that large and medium companies and foreign firms are more inclined to use historical returns on investment (arithmetic average) $(60 \%, 37 \%$ and $70 \%$, respectively) in comparison with smaller (small and micro) and domestic companies (24\%, $10 \%$ and $16 \%$, respectively). The results from our survey are presented in Figures 5 and 6.

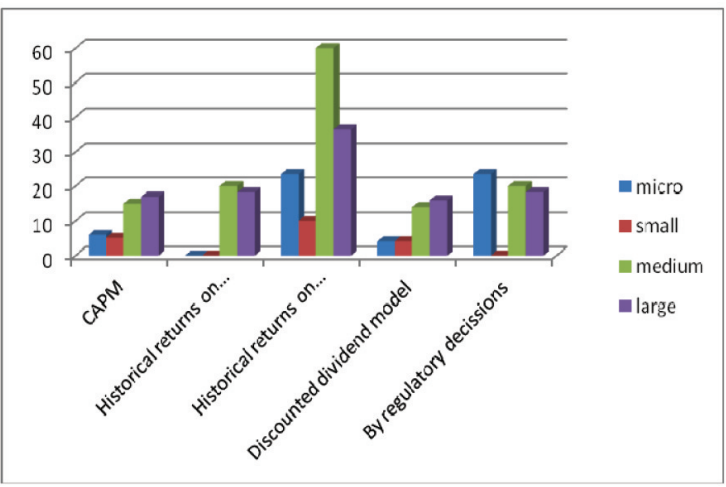

Figure 5: Percentage of CFOs who always or often use a given method according to firm size

(Results from the survey conducted by the authors)

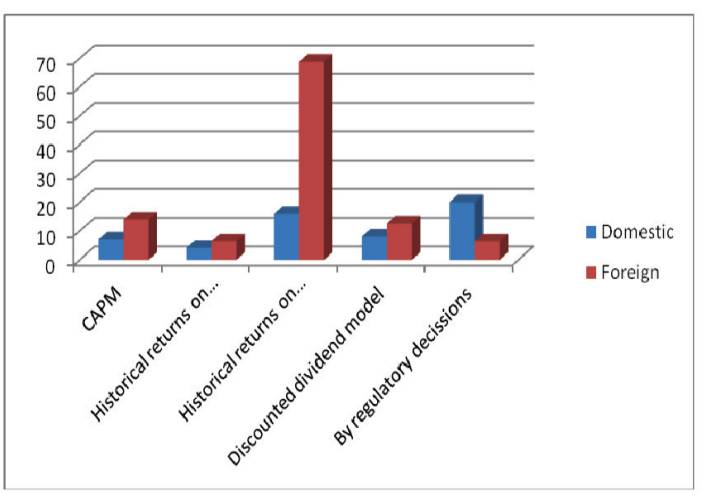

Figure 6: Percentage of CFOs who always and often use a given method according to the ownership

Finally, we have concluded that CAPM is not the dominant method for calculating cost of capital by both analyzing the overall sample and by dividing it into small subgroups following the size and the ownership of the firms within the sample. Consequently, our last hypothesis, H3 has been confirmed.

\section{Conclusion}

Our research confirmed that the majority of Serbian companies use the PP, PI and NPV as the dominant techniques for evaluating the project. Expectedly, the least used techniques are the SA, DPP and ARR. The less frequent usage of DCF ( $\mathrm{H} 1$ is confirmed) techniques results from inefficient and imperfect capital markets in Serbia and the difficulty in calculating the discount rate. Further, our findings indicate that large firms as well as multinational firms are more inclined to use DCF capital budgeting techniques and other sophisticated techniques in comparison with small and domestic companies. The latter confirms our $\mathrm{H} 2$ that factors such as size and ownership have influence on the choice of a capital budgeting technique. Furthermore, the results clearly show that the CAPM is not a dominant model for estimating the cost of capital in Serbia ( $\mathrm{H} 3$ is confirmed). The implementation of the CAPM is on the third place, where only $10 \%$ of the respondents stated that 
they used this method when calculating the cost of capital. The reason for such a limited usage of this method may be hidden in the fact that most of the companies from the sample are private firms and their betas could only be calculated through analyzing comparable publicly traded companies. However, the capital market in Serbia is not as efficient and liquid as capital markets in the USA and Europe, adding another obstacle in implementing the CAPM in Serbia.

Acknowledgment: This Research Paper was part of the project "Advancing Serbia's Competitiveness in the Process of EU Accession", no. 47028, in the period 2011-2015, financed by the Serbian Ministry of Science and Technological Development.

\section{REFERENCES}

[1] Andor, G., Mohanty, S., \& Toth, T. (2011). Capital budgeting practices: a survey of Central and Eastern European firms. World Bank, January, $1-45$.

[2] Brotherson T., Eades K., Harris R., Higgins R. (2013), "Best Practices in Estimating the Cost of Capital: An Update", Journal of Applied Finance, v. 23, iss. 1, pp. 15-33.

[3] Brounen D., Jong A., Koedijk K. (2004), "Corporate Finance in Europe: Confronting Theory with Practice", Financial Management, Vol. 33, No. 4, pp.71-101.

[4] Danielson M., Scott J. (2006), "The Capital Budgeting Decisions of Small Businesses", Journal of Applied Finance v.16, iss.2, pp.45-56.

[5] Dedi L., Orsag S. (2007), "Capital Budgeting Practices: A Survey of Croatian Firms", South East European Journal of Economics and Business, v. 2, iss. 1, pp. 59-67.

[6] Graham J., Harvey C., (2001) "The theory and practice of corporate finance: evidence from the field", Journal of Financial Economics 60, pp. 187-243

[7] Gitman, L.J., Forrester Jr., J.R., (1977). "A survey of capital budgeting techniques used by major U.S. firms", Financial Management 6, 66-71.

[8] Haas R., Peeters M.(2006), "The dynamic adjustment towards target capital structures of firms in transition economies", Economics of Transition, Volume 14 (1), pp. 133-169.

[9] Lintner, J., 1956. "Distribution of incomes of corporations among dividends, retained earnings, and taxes", American Economic Review 97-113.

[10] Moore J., Reichert K. (1983), "Analysis of the Financial Management Techniques Currently employed by Large US Companies", Journal of Business Finance and Accounting 10, (No.4 Winter), 623-645.

[11] Myers, S.C., Majluf, N. (1984) "Corporate Financing and investment decisions when firms have information that investors do not have", Journal of Financial Economics 13, 187-224.

[12] Vijay J., Ashwani K.(1995), "Capital Budgeting Practices in Corporate Canada", Financial Practice and Education, v. 5, iss. 2, pp. 37-43.

Receieved: November 2015. Accepted: March 2016.

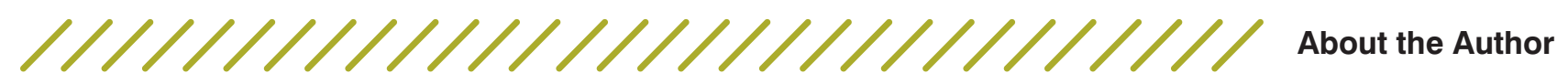

Lidija Barjaktarovic

Faculty of Economics, Finance and Administration, FEFA

Lidija Barjaktarovic has a PhD in Economic Sciences in the sectors of banking and finance. At the University Singidunum in Belgrade she teaches Banking, Risk

Management and Corporate Finances (from 2008). She has been Head of Master study programs of Business Economics and Public Sector Management at the University Singidunum since 2015. She had a banking career in the period from 1998 to 2008. It started in Jugobanka A.D. Belgrade, after which she moved to the Societe General

Yugoslav Bank a.d. Belgrade, and then to Raiffeisen Bank a.d. Belgrade in order to be promoted to the Head of the Regional Branch Central Serbia. In 2005 she moves to

Erste Bank a.d. Novi Sad to become a Director of Corporate Division. At the end of 2007 the Erste Group appoints her member of the Corporate Board and Corporate Working Group on the level of the Erste Holding Vienna. She published more than 30 papers in relevant journals and conferences, related to the banking and competitiveness of the Serbian banking sector, project finance, risk management and collection management. She took part in more than 20 projects within the bank (on local and group levels), University Singidunum and Serbian Ministry of Science and Technological Development.

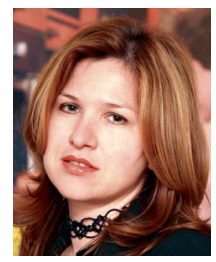




\section{Katarina Djulic \\ Faculty of Economics, Finance and Administration, FEFA}

Katarina Djulic is Associate Professor teaching the Corporate finance and Corporate governance courses at Faculty of Economics, Finance and Administration in Belgrade. She is also a Senior Consultant in the KPMG, Belgrade since January 2012, in charge or governance, risk and forensic projects. Ms. Djulic holds a Bachelor of Laws from the University of Belgrade, a Master of Laws (LL.M.) from Northwestern University, a Master in Public Policy from Harvard

University, JFK School of Government, and a PhD degree from the University of Belgrade, School of Economics. Before joining the KPMG, Ms. Djulic worked as project manager for the Serbian and Montenegrin Corporate Governance Projects of the International Finance Corporation (IFC), a part of the World Bank, which supports private sector sustainable development. Before the IFC, Ms Djulic worked as a legal adviser to firms in Belgrade and New York and, afterwards, at the Ministry of Finance of the Republic of Serbia, first as an adviser to the Minister and then as an Assistant Minister in charge of the Financial System Division. She also worked for European Bank for Reconstruction and Development in London in the Office of

General Council. Ms Djulic was a member of the Board of Directors in DDOR, Novi Sad, a member of the Supervisory Board in Jubanka, Beograd and a Chairwoman of the Supervisory Board in Central Securities Depositary and Clearing House, the Republic of Serbia.

\section{Renata Pindžo}

Ministry of Trade, Tourism and Telecommunication

Renata Pindžo, PhD is Assistant Professor of Investment Management and Investment Decision Process at the Faculty of Economy, Finance and Administration (FEFA), Singidunum University,

Belgrade. Since august 2014, she has been working as Assistant Minister in the Ministry of

Trade, Tourism and Telecommunications, in charge of the tourism sector. For a period of six years before that, she was engaged as the Assistant Minister in the Ministry of Economy and Regional Development and in the Ministry of Finance and Economy. She is a member of the National Council for the Tourism Development of the Republic of Serbia. Ms Pindžo graduated from the Faculty of Economics, The University of Belgrade where she obtained master degree

in 2003. In May 2011, she obtained her PhD. Her experience includes more than 13 years in

Management Consulting and Financial Advisory Services. She has gained knowledge by

providing consulting services to many domestic and international companies, including

financial institutions and local municipalities during her engagement in Deloitte. Also, as consultant, she was engaged in World Bank's projects related to restructuring and improving the competitiveness of Serbian economy. In the Economic Institute, Ms Pindžo worked on the research and market analysis projects. She has cooperated with many international institutions

(USAID, EAR, EBRD, DFID and GIZ) on complex projects of the restructuring of the Serbian economy. She is the author of numerous scientific papers.

Ana Vjetrov
Faculty of Economics, Finance and Administration, FEFA
avjetrov@fefa.edu.rs

Ana Vjetrov is a $\mathrm{PhD}$ researcher at the Singidunum University, Belgrade and she has been working as a Teaching Assistant at the Faculty of Economics, Finance and Administration (FEFA)

in Belgrade, Serbia, on the Business Banking and Investments Management modules since 2009 and on Corporate Finance since 2014. In addition to teaching and research, she has been involved in the organization of various conferences and was a member of the organizational board. As of recently, she is a member of LSE (London School of Economics) research team within the project Regional Support to Inclusive Education in South East Europe with special

focus on VET schools. In addition, she is involved in the Tempus project related to Career

Guidance since April 2013. Furthermore, during her studies she interned at Hypo Alpe Adria

Bank, KPMG Belgrade (auditing and financial consulting), and Banca Intesa for one year (corporate and retail banking). In 2010, Ms. Vjetrov led the team that won the second place at the International competition organized by CFA (Chartered Financial Analyst) in Budapest on the subject of the Analysis of business performance of the Magyar Telekom. Previous to her doctoral

research and teaching post, Ms. Vjetrov earned a Master's degree with Distinction in Finance and Banking at the Faculty of Economics, Finance and Administration and a Bachelor degree in the English Language and Literature, Faculty of Philology, Belgrade University. She has participated in various international conferences and published several articles.
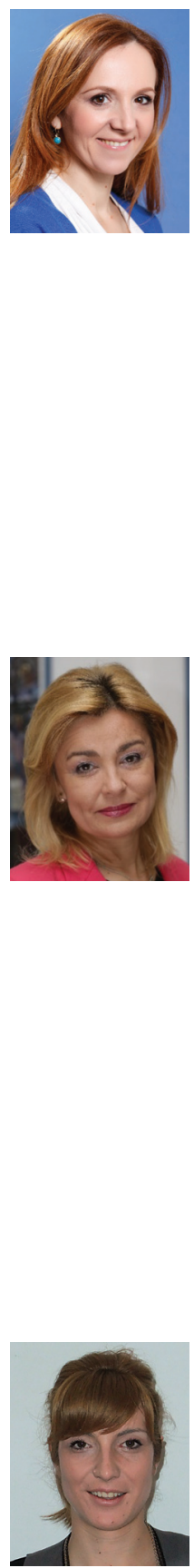